\title{
Multigram Synthesis and in Vivo Efficacy Studies of a Novel Multitarget Anti-Alzheimer's Compound
}

\author{
Irene Sola ${ }^{1}$, Elisabet Viayna ${ }^{1}$, Tània Gómez ${ }^{1}$, Carles Galdeano ${ }^{1}$, Matteo Cassina ${ }^{1}$, \\ Pelayo Camps ${ }^{1}$, Margherita Romeo ${ }^{2}$, Luisa Diomede ${ }^{2}$, Mario Salmona ${ }^{2}$, Pilar Franco ${ }^{3}$, \\ Mireille Schaeffer $^{3}$, Diego Colantuono ${ }^{3}$, David Robin ${ }^{3}$, Daniela Brunner ${ }^{4}$, Nicole Taub ${ }^{4}$, \\ Birgit Hutter-Paier ${ }^{4}$ and Diego Muñoz-Torrero ${ }^{1, *}$
}

1 Laboratori de Química Farmacèutica (Unitat Associada al CSIC), Facultat de Farmàcia and Institut de Biomedicina (IBUB), Universitat de Barcelona, Av. Joan XXIII, 27-31, Barcelona E-08028, Spain; E-Mails: irenesola872@gmail.com (I.S.); elisabet.viayna@gmail.com (E.V.); tania.gomez.nadal@gmail.com (T.G.); cargalcan@hotmail.com (C.G.); matteo.cassina01@universitadipavia.it (M.C.); camps@ub.edu (P.C.)

2 Department of Molecular Biochemistry and Pharmacology, IRCCS-Istituto di Ricerche Farmacologiche "Mario Negri", Via La Masa 19, Milan 20156, Italy;

E-Mails: margherita.romeo@marionegri.it (M.R.); luisa.diomede@marionegri.it (L.D.); mario.salmona@marionegri.it (M.S.)

3 Chiral Technologies Europe, Parc d'Innovation, Bd. Gonthier d'Andernach, Illkirch F-67400, France; E-Mails: pfranco@chiral.fr (P.F.); mschaeffer@chiral.fr (M.S.); dcolantuono@chiral.fr (D.C.); drobin@chiral.fr (D.R.)

4 Neuropharmacology Department of QPS Austria-Gmbh, Parkring 12, Grambach 8074, Austria; E-Mails: Daniela.Brunner@qps.com (D.B.); Nicole.Taub@qps.com (N.T.);

Birgit.Hutter-Paier@qps.com (B.H.-P.)

* Author to whom correspondence should be addressed; E-Mail: dmunoztorrero@ub.edu; Tel.: +34-93-402-4533; Fax: +34-93-403-5941.

Academic Editor: Jean Jacques Vanden Eynde

Received: 22 January 2015 / Accepted: 3 March 2015 / Published: 10 March 2015

\begin{abstract}
We describe the multigram synthesis and in vivo efficacy studies of a donepezil-huprine hybrid that has been found to display a promising in vitro multitarget profile of interest for the treatment of Alzheimer's disease (AD). Its synthesis features as the key step a novel multigram preparative chromatographic resolution of intermediate racemic huprine $\mathrm{Y}$ by chiral HPLC. Administration of this compound to transgenic
\end{abstract}


CL4176 and CL2006 Caenorhabditis elegans strains expressing human A $\beta 42$, here used as simplified animal models of $\mathrm{AD}$, led to a significant protection from the toxicity induced by $A \beta 42$. However, this protective effect was not accompanied, in CL2006 worms, by a reduction of amyloid deposits. Oral administration for 3 months to transgenic APPSL mice, a well-established animal model of AD, improved short-term memory, but did not alter brain levels of $A \beta$ peptides nor cortical and hippocampal amyloid plaque load. Despite the clear protective and cognitive effects of AVCRI104P4, the lack of $\mathrm{A} \beta$ lowering effect in vivo might be related to its lower in vitro potency toward $\mathrm{A} \beta$ aggregation and formation as compared with its higher anticholinesterase activities. Further lead optimization in this series should thus focus on improving the anti-amyloid/anticholinesterase activity ratio.

Keywords: disease-modifying anti-Alzheimer drugs; multitarget drugs; neuroprotection; animal models of Alzheimer's disease; multigram preparative chromatographic resolution

\section{Introduction}

Alzheimer's disease (AD) currently constitutes a huge human tragedy due to its devastating effects on the quality of life of patients, and its increasingly higher prevalence and mortality. AD currently affects some 44 million people worldwide and is among the top ten leading causes of death in developed countries, and the trend is that these figures will keep on increasing in the next decades [1].

The drugs marketed so far to combat AD were developed to alleviate the symptoms of the disease, i.e., the cognitive and functional decline mainly caused by a cholinergic deficit in the central nervous system (CNS). As long as more players in the neuropathogenesis of $\mathrm{AD}$, placed upstream of the neurotransmitter deficits that originate AD symptomatology, have been known, intensive research has been conducted to develop new drugs able to modulate those upstream targets and, hence, the underlying mechanisms of the disease. A number of promising drug candidates have been developed in the past decade to separately hit one of the putative key players of AD neuropathogenesis, prominently the formation or the aggregation of the $\beta$-amyloid peptide $(\mathrm{A} \beta)[2,3]$. However, none of these single-target disease-modifying agents has demonstrated to be effective and safe in clinical trials, so far. In this context, alternative approaches are worth of consideration in the pursuit of effective drugs that may prevent, stop or delay $\mathrm{AD}$ progression. An alternative approach, which is gaining adepts in the last years, is based on the consideration of $\mathrm{AD}$ as a pathological network where several protein targets of similar relevance are interconnected, leading to a robust system that cannot be perturbed by separate modulation of any single target [4]. The therapeutic strategy that follows from this novel conception of the disease is evident, i.e., the simultaneous modulation of several important targets of the disease network seems to be a more realistic option for tackling the neurodegenerative process of AD [5-9].

Indeed, this approach has proved successful in recent in vivo studies with some multitarget compounds such as memoquin [10] and IQM-622 [11] in different mouse models of AD, where these compounds have been shown to be able to address the underlying mechanisms of neurodegeneration.

We have recently developed a new structural family of hybrid compounds, which were designed by combination of pharmacophoric moieties of two potent inhibitors of acetylcholinesterase (AChE), 
namely donepezil and huprine Y [12]. The rationale behind this design was to enable interactions at different sites of a particular target, simultaneously affecting two important targets in the context of $\mathrm{AD}$ treatment. Thus, the novel donepezil-huprine hybrids were decorated with structural motifs as to enable their simultaneous interactions at three different sites all along the $20 \AA$-deep catalytic gorge of the enzyme AChE [13], namely the active, midgorge and peripheral sites, which should lead to a potent cholinergic effect. On the other hand, this multiple-site binding to AChE was expected to lead to a disruption of the binding of the $\mathrm{AChE}$ peripheral site to $\mathrm{A} \beta[14,15]$, and hence, to an inhibition of the $\mathrm{A} \beta$ proaggregating action of $\mathrm{AChE}[16,17]$. Indeed, in vitro these donepezil-huprine hybrids were endowed with both activities for which they had been rationally designed. Additionally, screening at other targets of interest for $\mathrm{AD}$ treatment revealed that these hybrids can also inhibit in vitro butyrylcholinesterase $(\mathrm{BChE}), \mathrm{A} \beta$ self-aggregation and $\mathrm{BACE}-1$, the enzyme that catalyzes the first and rate-limiting step of the proteolytic cleavage of the amyloid precursor protein (APP) to A $\beta$, thereby expanding the in vitro multitarget profile of these compounds. AVCRI104P4 (Scheme 1) emerged as the lead of this structural family, by virtue of its interesting in vitro multitarget profile (Table 1).

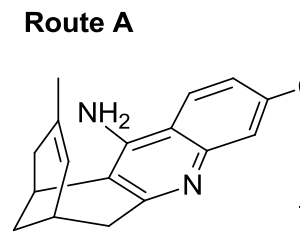

$( \pm)-1$ $1 \times 100 \mathrm{mg}+3 \times 150 \mathrm{mg}$
Chiral MPLC

microcrystalline cellulose triacetate

96\% EtOH $\quad(-)-(7 S, 11 S)-1 \quad(+)-(7 R, 11 R)-1$

$189 \mathrm{mg}(>90 \%$ ee) $140 \mathrm{mg}(>80 \%$ ee $)$

(upgrading to $>99 \%$ ee by

recrystallization of hydrochloride salts)
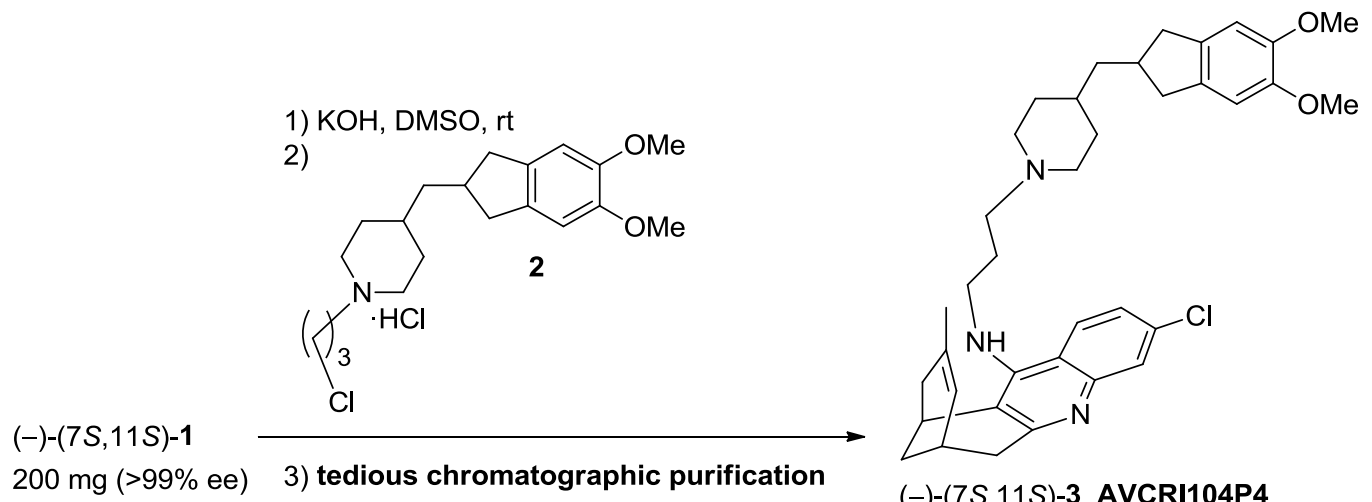

(-)-(7S,11S)-3, AVCRI104P4

$64 \mathrm{mg}(>99 \%$ ee, $15 \%$ yield)

Route B

1) $\mathrm{KOH}, \mathrm{DMSO}, \mathrm{rt}$

$( \pm)-1$

2) 2

Chiral HPLC

(chromatographic purification + resolution)

Scheme 1. Reported low scale synthesis of AVCRI104P4 (route A) and envisaged alternative sequence (route B). 
Table 1. In vitro and ex vivo biological profile of AVCRI104P4 relative to the parent compounds donepezil and huprine Y [12].

\begin{tabular}{|c|c|c|c|c|c|c|}
\hline Compound & hAChE IC I0 $_{50}$ & hBChE IC 50 nM & BACE-1 IC I0 $_{50}$ & $\begin{array}{l}\text { A } \beta \text { Aggreg. } \\
\% \text { Inhibition } \\
\text { at } 10 \mu \mathrm{M}^{\text {a }}\end{array}$ & $\begin{array}{c}\text { PAMPA-BBB } \\
P_{\mathrm{e}}\left(10^{-6} \mathrm{~cm} \cdot \mathrm{s}^{-1}\right)^{\mathrm{b}} \\
\text { (Prediction) }\end{array}$ & $\begin{array}{c}\text { Ex Vivo Studies } \\
\text { c } \\
\% \text { Inhibition } \\
\text { Brain AChE }\end{array}$ \\
\hline AVCRI104P4 & 2.61 & 349 & 11.0 & 29 & $11.4(\mathrm{CNS}+)$ & $59 \%$ at $5 \min ^{d}$ \\
\hline Donepezil & 21.4 & 7273 & 11.3 & $<5$ & $25.2(\mathrm{CNS}+)$ & $73 \%$ at $5 \min ^{e}$ \\
\hline (-)-Huprine Y & 0.43 & 247 & $\mathrm{Nd}^{\mathrm{f}}$ & 10.2 & $18.2(\mathrm{CNS}+)$ & $97 \%$ at $20 \mathrm{~min}$ \\
\hline
\end{tabular}

${ }^{\mathrm{a}}[\mathrm{A} \beta 1-42] /[$ inhibitor $]=5: 1 ;{ }^{\mathrm{b}}$ Permeability $\left(P_{\mathrm{e}}\right)$ results from the PAMPA-BBB assay [18], AVCRI104P4 dissolved in PBS/EtOH 70:30, donepezil and (-)-huprine Y dissolved in PBS/EtOH 80:20; ${ }^{c} \%$ Inhibition of OF1 mice brain AChE at the indicated time after i.p. administration of $10 \mu \mathrm{mol} \cdot \mathrm{kg}^{-1}$ of the compound versus

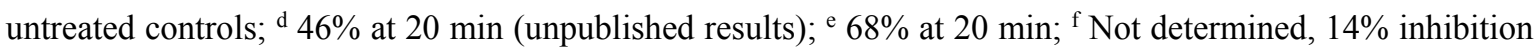
at $5 \mu \mathrm{M}$.

It is generally believed that multitarget compounds should display similar in vitro potencies at their different biological targets, usually within one order of magnitude of each other, which might lead to a similar level of occupancy of those targets in vivo [19]. However, it has been suggested that the potencies at the different targets may not necessarily have to lie within such a narrow range, so that in vivo studies of a lead candidate may be very helpful to ascertain the adequate ratio of in vitro activities [19]. Thus, even though the two main in vitro activities of AVCRI104P4 might seem not properly balanced, with anticholinesterase activities in the nanomolar (AChE) to submicromolar (BChE) range and anti-amyloid activity (BACE-1) in the low micromolar range, in vivo testing of this compound was envisaged to definitely find out whether the different activities of this lead might arise also in vivo.

Herein, we describe the synthesis at a multigram scale of AVCRI104P4, which involves as the key step a novel multigram preparative chromatographic resolution of the intermediate racemic huprine $\mathrm{Y}$ by chiral HPLC, and the in vivo efficacy studies of AVCRI104P4 in different animal models of AD, two transgenic Caenorhabditis elegans strains expressing A $\beta 42$ (CL4176 and CL2006) as simplified invertebrate models, and transgenic APPsL mice, as a well-established animal model. Particularly, the protective effects of AVCRI104P4 against the paralysis induced in CL4176 by the oligomeric production of A $\beta 1-42$ and in CL2006 by the constitutive expression of A $\beta 3-42$, leading to both oligomeric and fibrillar protein deposition, have been assessed. Moreover, the behavioural effects of AVCRI104P4 in APPSL transgenic mice orally treated for 3 months, as well as its effects on A $\beta$ levels in cerebrospinal fluid (CSF) and brain homogenates, and on the amyloid load in cortex and hippocampus have been also determined.

\section{Results and Discussion}

\subsection{Synthesis of AVCRI104P4}

AVCRI104P4 had been previously synthesized at a centigram scale (64 mg) [12]. However, the planned in vivo studies required multigram amounts of this compound, thereby making it necessary a scale-up the synthesis. 
The low scale synthesis of AVCRI104P4 involved the preparative chromatographic resolution of racemic huprine $\mathrm{Y}(\mathbf{1})$, the synthesis of the donepezil-derived chloropropylpiperidine 2, and the final coupling of enantiopure (-)-(7S,11S)-huprine $\mathrm{Y}$ with 2 (route A in Scheme 1) [12]. However, because purification of AVCRI104P4 by standard silica gel column chromatography had been a quite difficult, low yield, and tedious task in the low scale synthesis [12], a quite attractive option for the scale-up synthesis might involve the direct preparative chiral chromatography of multigram amounts of the crude racemic final compound, inasmuch as separation of AVCRI104P4 from its enantiomer and from unreacted starting materials or other byproducts formed in the reaction might be done at once, thereby avoiding a previous achiral chromatographic step (route B in Scheme 1). Thus, a crucial decision before starting the scaled up synthesis of AVCRI104P4 was the step at which the chromatographic resolution should be done.

In this context, samples of pure racemic $\mathbf{1}$, pure racemic $\mathbf{3}$, and crude racemic $\mathbf{3}$ were subjected to an exhaustive screening in liquid and supercritical fluid chromatography (LC and SFC), in order to identify suitable preparative methods and subsequently compare them.

A number of chiral stationary phases (CSPs) were able to separate both racemates for analytical purposes. Nevertheless, for the preparative application, the first important preliminary observation was the limited solubility of the three samples in many organic solvents. Therefore, the screening of mobile phases had to be dictated by the solubility, otherwise, the preparative resolution would be inefficient. Dichloromethane (DCM), EtOAc and THF mixtures were chosen as preferred options and this was conditioning the type of CSPs to be used.

The three samples were screened on polysaccharide-derived columns, having the chiral selector immobilized onto the silica backbone. Those phases (CHIRALPAK IA, IB and IC) were combining a high loading capacity with the possibility of using the above mentioned solvents as mobile phases and/or injection solvents [20-22]. Separations for the enantiomeric pairs were identified in LC and SFC mode, however, LC seemed to be better adapted to these molecules.

One of the main advantages of SFC at preparative scale is the possibility of working in $\mathrm{CO}_{2}$ mixtures with a relatively low percentage of co-solvent (usually 10\%-20\%). However, both 1 and 3 were rather retained in SFC mode, so that higher co-solvent percentages were needed and solubility was an issue. Therefore, the SFC option was quickly discarded.

Taking into account all these elements, the screening undertaken in LC was reviewed and put into perspective. The best option found was the resolution of the racemic precursor, huprine $\mathrm{Y},( \pm)-\mathbf{1}$, on CHIRALPAK IC with a mobile phase composed by a DCM/i-PrOH mixture (details may be seen in the Experimental Section). The main reasons for such a decision were: (i) the impossibility of isolating $(-)-(7 S, 11 S)-3$ (AVCRI104P4) in a single chromatographic step from the crude material and (ii) the low solubility of the molecules.

In Figure 1A the initially identified resolution of the peaks in the crude material at analytical level (with peak identification) can be found. Such conditions involved $50 \%$ of $n$-heptane in the mobile phase and the sample was only sparingly soluble. It was necessary then optimizing the method by avoiding the alkane and modulating retention, as well as recognition with a DCM/i-PrOH mixture (see chromatogram of the crude in Figure 1B). The combination of DCM with other solvents such as THF was tested, but found to be less adapted. In DCM/i-PrOH, (-)-3 (AVCRI104P4) and (-)-1 ((-)-huprine Y)) 
co-elute and the two enantiomers of $\mathbf{3}$ hardly reach baseline separation. Therefore, it seemed that the preparative resolution of racemic huprine $\mathrm{Y},( \pm)-\mathbf{1}$, was the best option (Figure 1C).

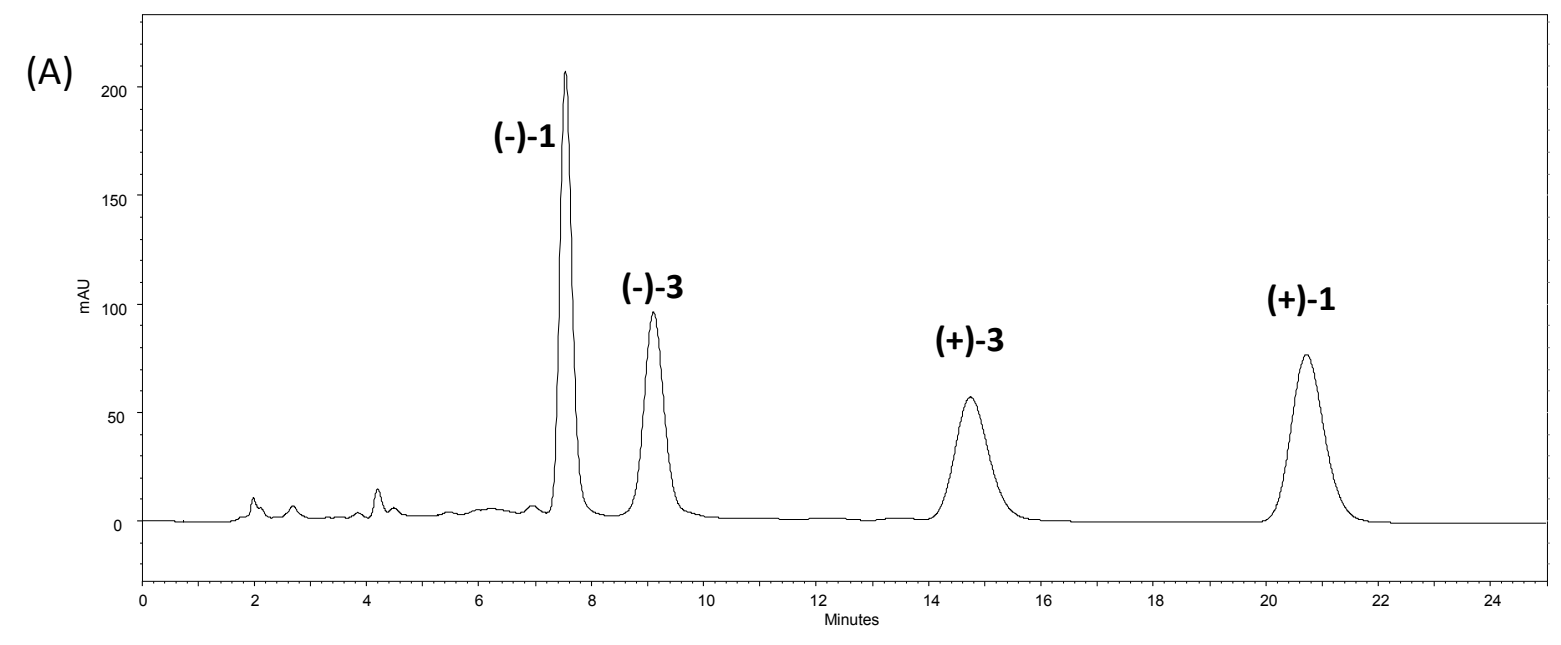

(B)

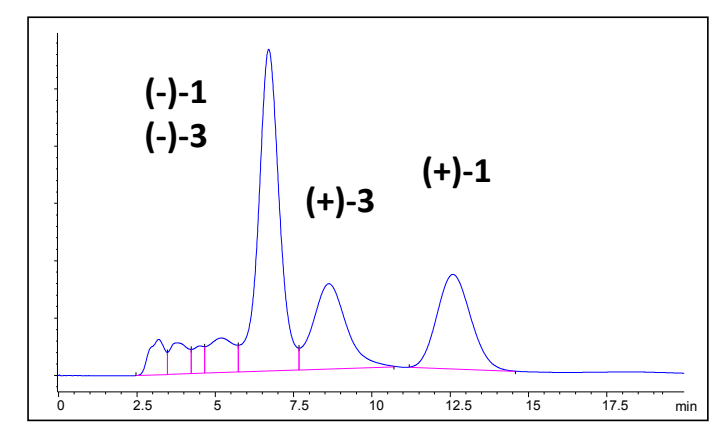

(C)

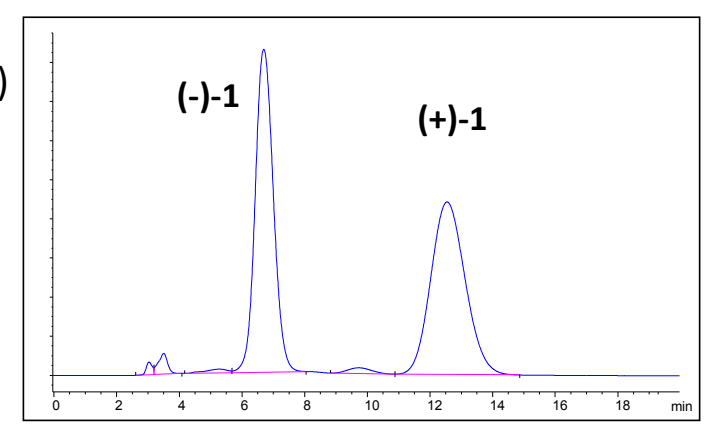

Figure 1. Chromatographic separation by HPLC of (A) crude mixture of racemic $\mathbf{1}$ and $\mathbf{3}$ on CHIRALPAK IC $(5 \mu \mathrm{m}, 250 \times 4.6 \mathrm{~mm})$ in $n$-heptane/DCM/EtOH/DEA 50:50:1:0.1, $2 \mathrm{~mL} / \mathrm{min}, 25{ }^{\circ} \mathrm{C}$; (B) crude mixture of racemic $\mathbf{1}$ and $\mathbf{3}$ on CHIRALPAK IC $(20 \mu \mathrm{m}$, $250 \times 4.6 \mathrm{~mm})$ in DCM/i-PrOH/DEA 95:5:0.1, $1 \mathrm{~mL} / \mathrm{min}, 25^{\circ} \mathrm{C}$; (C) Racemic 1 on CHIRALPAK IC $(20 \mu \mathrm{m}, 250 \times 4.6 \mathrm{~mm})$ in DCM/i-PrOH/DEA 95:5:0.1, $1 \mathrm{~mL} / \mathrm{min}, 25^{\circ} \mathrm{C}$.

Intermediate racemic huprine $Y( \pm)-\mathbf{1}$, and chloroderivative $\mathbf{2}$ were synthesized at multigram scale following the described procedures [12,23-27], with some necessary modifications due to the scale of work (see Supplementary Materials).

At this point, taking into account the results of the chromatographic screening (Figure 1), we undertook the multigram chromatographic resolution of intermediate huprine $Y,( \pm)-\mathbf{1}$. As outlined in Scheme 1, we had performed the low scale synthesis of enantiopure huprines by preparative chromatographic resolution of the corresponding racemates, using a medium pressure liquid chromatography (MPLC) equipment, microcrystalline cellulose triacetate as the chiral stationary phase and $96 \% \mathrm{EtOH}$ as the eluent [26]. Indeed, we had separated (-)-(7S,11S)-huprine Y (189 $\mathrm{mg},>90 \%$ ee) and $(+)-(7 R, 11 R)$-huprine $\mathrm{Y}(140 \mathrm{mg},>80 \%$ ee $)$ using this methodology, after four successive injections of the racemic compound $(1 \times 100 \mathrm{mg}+3 \times 150 \mathrm{mg})$ [26]. The enantiomeric excesses were subsequently upgraded upon conversion into the corresponding hydrochloride salts followed by 
recrystallization. Obviously, this laboratory equipment and scale of work were by far insufficient to perform the chromatographic resolution of decagram amounts of racemic huprine $\mathrm{Y}$.

The large scale chromatographic resolution of huprine Y was carried out by preparative HPLC on a $66 \mathrm{~g}$ batch (scale factor $\times 120$ relative to the low scale synthesis) using a CHIRALPAK IC column (cellulose tris(3,5-dichlorophenylcarbamate)) and a mixture DCM/i-PrOH/DEA 90:10:0.1 as the eluent, to yield $>99 \%$ ee (-)-(7S,11S)-huprine Y (28.5 g) and (+)-(7R,11R)-huprine Y (24.7 g) (Scheme 2). The estimated throughput would be $72 \mathrm{~g}$ of $(-)-(7 S, 11 S)$-huprine $\mathrm{Y}$ per day using a $250 \times 110$ mm-column in a $24 / 24 \mathrm{~h}$ process by batch chromatography (144 $\mathrm{g}$ of racemate processed), i.e., $96 \mathrm{~g}$ of racemate per $\mathrm{kg}$ of CSP and day. If such a method were translated to continuous chromatography (Simulated Moving Bed, SMB) it would involve about $300 \mathrm{~g}$ of pure enantiomer per $\mathrm{kg}$ of CSP and day.

Overall, the multigram chromatographic resolution of huprine $\mathrm{Y}$ was performed not only with the necessary much higher loading capacity but also with higher enantiopurity and resolution efficiency, so that amounts of both enantiomers $>150$-fold larger than those obtained in the low scale synthesis were obtained.

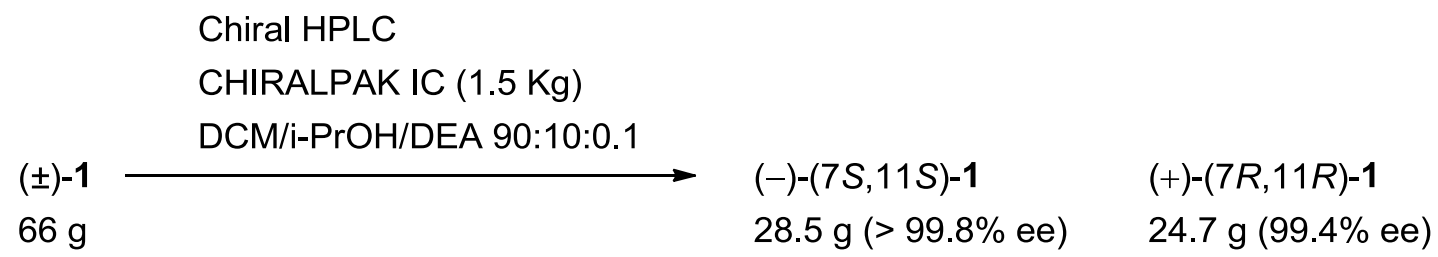
1) $\mathrm{KOH}, \mathrm{DMSO}$, rt, $4 \AA$ molecular sieves
$(-)-(7 S, 11 S)-1$
$3.34 \mathrm{~g}(>99.8 \% \mathrm{ee})$
2) 2, DMSO, rt
3) Column chromatography purification
$(-)-(7 S, 11 S)-3$, AVCRI104P4
$2.94 \mathrm{~g}(>99.8 \%$ ee, $42 \%$ yield $)$

Scheme 2. Novel multigram HPLC resolution of huprine Y and scale-up synthesis of AVCRI104P4.

Finally, reaction of enantiopure (-)-(7S,11S)-huprine Y (3.34 g, >99.8\% ee) with chloroderivative 2 in the presence of $\mathrm{KOH}$ in DMSO afforded AVCRI104P4 (2.94 g) in significantly higher yield than in the low scale procedure ( $42 \%$ isolated yield, after silica gel column chromatography purification $v s$. $15 \%$ isolated yield in the low scale synthesis, Scheme 2). After several runs of this reaction, a total amount of $14 \mathrm{~g}$ of AVCRI104P4 was finally obtained, which allowed us to undertake the planned in vivo studies.

\subsection{In Vivo Studies in C. elegans}

Before testing AVCRI104P4 in a mouse model of AD, we conducted some in vivo studies in a simplified invertebrate model, namely in Caenorhabditis elegans. This nematode offers a number of advantages such as a short lifecycle, high reproduction profile, experimental flexibility, and ease to knockdown gene expression, among others, which has prompted the creation of different strains that express amyloidogenic proteins involved in different neurodegenerative disorders [28]. Thus, transgenic $C$. elegans AD models have been used to study pathogenic pathways and alterations of gene expression induced by $\mathrm{A} \beta[29,30]$, and, recently, also for the evaluation of the neuroprotective and anti-amyloidogenic effects of some multitarget anti-Alzheimer compounds [31-33]. 
Herein, we determined the ability of AVCRI104P4 to protect from the toxicity induced by human A $\beta 42$ expression and accumulation, which results in plaque deposits similar to those observed in the brain of AD patients [34]. To this end, the transgenic C. elegans strain CL2006, constitutively expressing human A $\beta 3-42$ in the body wall muscle cells [35,36], was here used. This strain is characterized by a progressive and age-related reduction of the motility due to the expression of A $\beta 3-42$ which results in the formation of both fibrils and oligomers [36]. The CL4176 transgenic C. elegans strain, in which the human A $\beta 1-42$ expression was induced by increasing the temperature of culture, was also used. In this strain, the paralysis phenotype is specifically associated with the deposition of oligomers in their muscle cells without the formation of amyloid aggregates [36,37]. Previous results obtained in CL4176 nematodes treated with anti-amyloidogenic tetracyclines supported the toxic role of oligomers [36-38]. CL802 nematodes, which do not express the A $\beta$ transgene [34], were used as controls.

In CL2006 worms the administration of $100 \mu \mathrm{M}$ AVCRI104P4 for $24 \mathrm{~h}$ caused a little, albeit significant, reduction of $26.5 \%$ of the $A \beta 3-42$-induced paralysis, significantly lower than that occurring with $100 \mu \mathrm{M}$ tetracycline (74.6\% reduction of paralysis) (Figure 2A). The feeding of CL802 worms with $100 \mu \mathrm{M}$ AVCRI104P4 for $24 \mathrm{~h}$ did not modify their paralysis $(2.3 \% \pm 1.0 \%$ and $2.7 \% \pm 0.9 \%$ of percentage of paralyzed worms for CL802 nematodes fed with vehicle and AVCRI104P4, respectively), with this result being indicative of the fact that this compound did not induce any unspecific and/or toxic effect in control nematodes.

We then investigated the effect of AVCRI104P4 on the degree of A $\beta$ amyloidosis by evaluating the number of aggregate deposits in the head region of CL2006 transgenic worms. To this end, synchronized worms were grown at $16{ }^{\circ} \mathrm{C}$ for $72 \mathrm{~h}$ and treated with either vehicle or AVCRI104P4 $(100 \mu \mathrm{M}$, $100 \mu \mathrm{L} /$ plate) for $24 \mathrm{~h}$. Nematodes were then stained with the X-34 dye, specifically recognizing $\beta$-amyloid deposits [36]. AVCRI104P4 did not reduce the X-34 positive spots (Figure 2B), which indicated that the protective effect of the compound cannot be ascribed to its ability to affect $A \beta$ fibril deposition. The dot blot analysis performed on worm lysates with the WO2 total A $\beta$-specific antibody (Figure $2 \mathrm{C}$ ) indicated that there were no differences in the $\mathrm{A} \beta$-immunoreactive signal between worms treated for $24 \mathrm{~h}$, with vehicle or $100 \mu \mathrm{M}$ AVCRI104P4. These data indicate that the ability of AVCRI104P4 to counteract $A \beta$ toxicity was not linked to its ability to modify the amount of $A \beta$ produced and/or degraded by transgenic nematodes.

The effect of AVCRI104P4 on CL4176 worms was also investigated since this strain represents a convenient model to specifically study the in vivo effects of $\mathrm{A} \beta$ oligomers and to screen for potential anti-oligomer compounds [35,36]. Administration of $100 \mu \mathrm{M}$ AVCRI104P4, $18 \mathrm{~h}$ after the rise of temperature, reduced the paralysis by $47.5 \%$, similarly to $100 \mu \mathrm{M}$ tetracycline $(45.4 \%$ reduction of paralysis) (Figure 3A). Aldicarb, an AChE inhibitor, did not exert any protective action (Figure 3A), indicating that the protective activity of AVCRI104P4 against the toxicity exerted by oligomeric A $\beta$ was specific and unrelated to the inhibition of AChE. In addition, AVCRI104P4 protected CL4176 nematodes from the $\mathrm{A} \beta$-induced paralysis in a dose-dependent manner (Figure 3B). The drug concentration that inhibited paralysis by $50 \%$ ( $\mathrm{IC}_{50}$ ) was $34.0 \pm 1.2 \mu \mathrm{M}$ ( $n=100$ worms/group, mean $\pm \mathrm{SE})$, similar to that obtained for tetracycline $(39.9 \pm 1.5 \mu \mathrm{M})[36]$.

The protective effect of AVCRI104P4 in CL4176 worms was not associated to its ability to modify the amount of $A \beta$ produced by transgenic nematodes, as indicated by the dot blot analysis performed with the WO2 total A $\beta$-specific antibody (Figure 3C). These results indicate that the protective effect 
of AVCRI104P4 against A $\beta$ toxicity was greater in CL4176 than in CL2006 nematodes, suggesting that this drug may exert its activity against the oligomeric assemblies of $A \beta$, without affecting amyloid plaque deposition and independently from its AChE inhibitory activity.
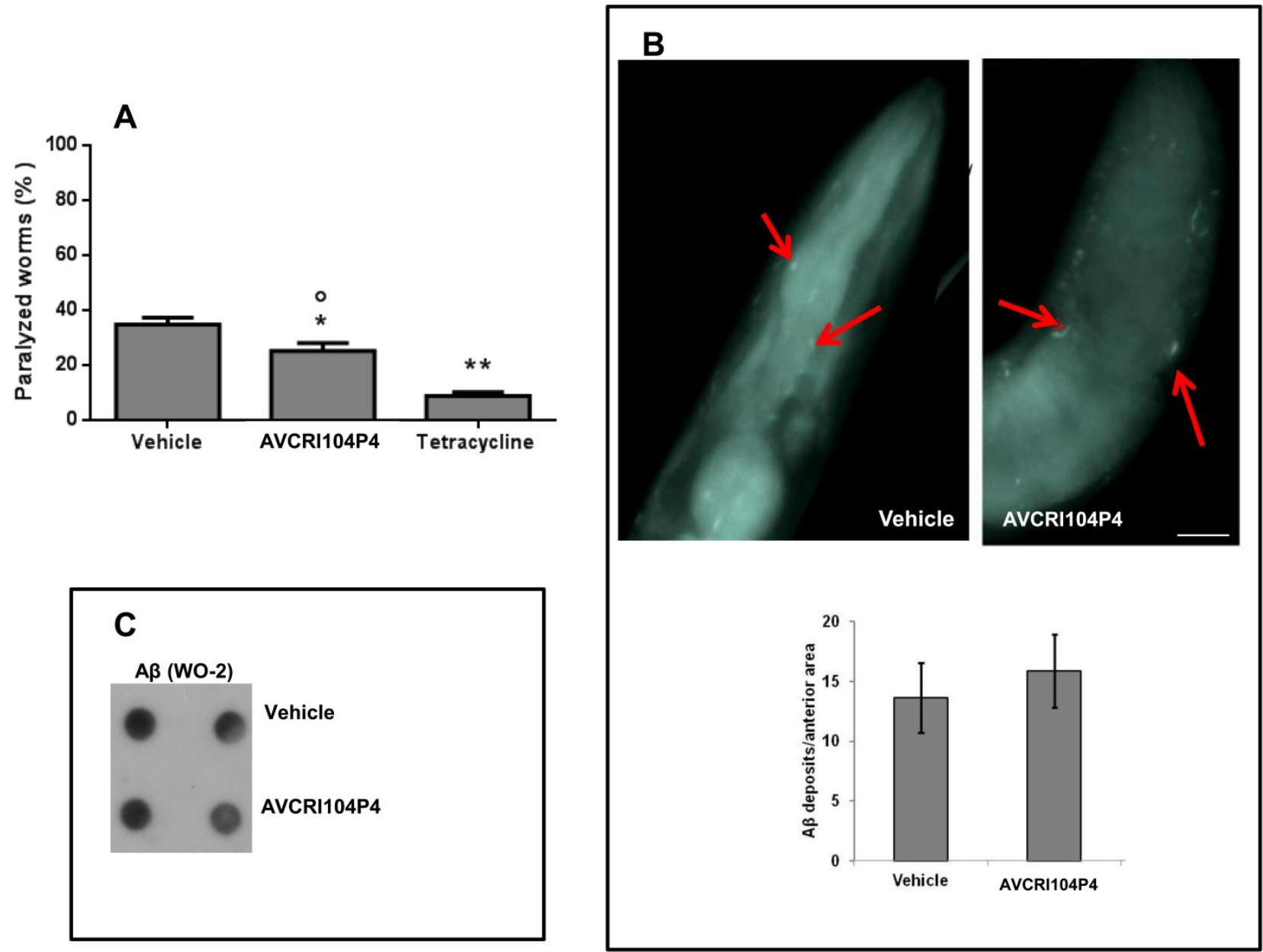

Figure 2. Effect of AVCRI104P4 administration on the paralysis of CL2006 nematodes and A $\beta$ deposition. (A) Percentage of CL2006 paralyzed worms treated with AVCRI104P4. Nematodes were treated for $24 \mathrm{~h}$ with $100 \mu \mathrm{M}$ AVCRI104P4 or $100 \mu \mathrm{M}$ tetracycline (positive control) and the number of nematodes that did not move was scored. Data from three independent experiments ( $n=100$, per group) are indicated as $\% \pm$ S.D. of paralyzed nematodes to worms treated with vehicle. $* p<0.05$ and $* *<0.01$ vs. vehicle-treated CL2006 nematodes and ${ }^{\circ} p<0.05 v s$. CL2006 worms treated with tetracycline (One-way ANOVA test); (B) X-34 positive amyloid deposits in CL2006 worms treated with vehicle or $100 \mu \mathrm{M}$ AVCRI104P4. Synchronized CL2006 nematodes were treated with vehicle or $100 \mu \mathrm{M}$ AVCRI104P4 for $24 \mathrm{~h}$, amyloid plaques were stained with X-34 dye and visualized at short wavelength excitation. Scale bar $20 \mu \mathrm{m}$. Amyloid deposits in the anterior area of worms, indicated with red arrows, were quantified in nematodes treated with vehicle $(n=20)$ or $100 \mu \mathrm{M}$ AVCRI104P4 $(n=20)$, by counting the number of X-34 positive spots; (C) Effect of $100 \mu \mathrm{M}$ AVCRI104P4 administration on total A $\beta$ in CL2006 worms. Representative dot blot of total A $\beta$ (WO2) on lysates ( $5 \mu \mathrm{g}$ ) of CL2006 transgenic worms treated with vehicle or $100 \mu \mathrm{M}$ AVCRI104P4 for $24 \mathrm{~h}$. 

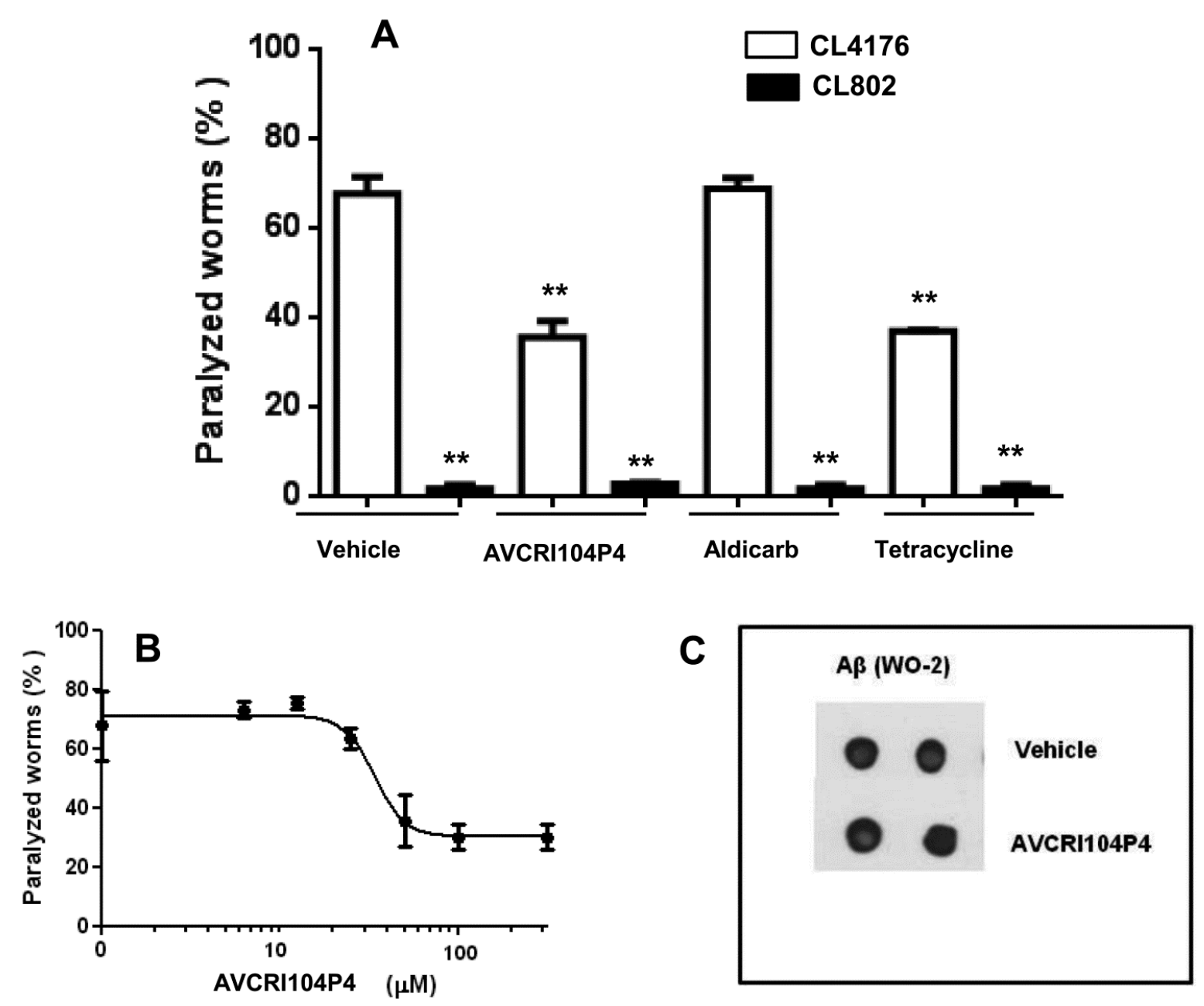

Figure 3. Effect of AVCRI104P4 on the paralysis of CL4176 worms. (A) Percentage of paralyzed CL4176 and CL802 worms fed with $100 \mu \mathrm{M}$ AVCRI104P4, $100 \mu \mathrm{M}$ aldicarb, or $100 \mu \mathrm{M}$ tetracycline $18 \mathrm{~h}$ after the temperature increase. Paralysis was evaluated $42 \mathrm{~h}$ after the temperature rise. Data from three independent experiments $(n=100$, per group) are indicated as $\% \pm$ S.D. of paralyzed nematodes to worms treated with vehicle. $* * p<0.01$ vs. vehicle-treated CL4176 nematodes (One-way ANOVA test); (B) Dose-dependent protective effect of AVCRI104P4 on the paralysis of CL4176 worms. The transgene expression was induced in synchronized worms after $54 \mathrm{~h}$ at $16{ }^{\circ} \mathrm{C}$, by raising the temperature to $24{ }^{\circ} \mathrm{C}$. Nematodes were fed with different concentrations of AVCRI104P4 (5-300 $\mu \mathrm{M}, 100 \mu \mathrm{L} /$ plate) $18 \mathrm{~h}$ after raising the temperature. The number of paralyzed worms was scored $42 \mathrm{~h}$ after the temperature rise. Data from three independent experiments ( $n=100$, per group) are indicated as $\% \pm$ S.D. of paralyzed nematodes to worms treated with vehicle; (C) Effect of $100 \mu \mathrm{M}$ AVCRI104P4 administration on total $\mathrm{A} \beta$ in CL4176 worms. Representative dot blot of total $\mathrm{A} \beta$ (WO2) on lysates (5 $\mu \mathrm{g}$ ) of CL4176 transgenic worms treated with vehicle or $100 \mu \mathrm{M}$ AVCRI104P4 as described.

\subsection{In Vivo Studies in Transgenic APPSL Mice}

The effects of AVCRI104P4 on cognition and amyloid pathology were evaluated in vivo in a well-established animal model of $\mathrm{AD}$, namely in $\mathrm{APP}_{\mathrm{SL}}$ transgenic mice. These transgenic mice 
develop early and progressive amyloid plaque deposition in cortex and hippocampus as well as cognitive impairment, thereby being widely used as preclinical animal models of AD. Twenty-four

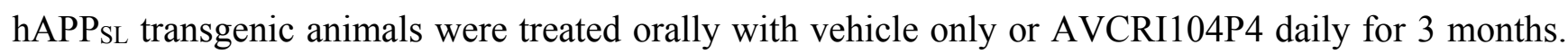
Starting with a dose of $10 \mathrm{mg} / \mathrm{kg}$ of AVCRI104P4, the treatment dose was increased in a staggered manner, i.e., weekly $+5 \mathrm{mg} / \mathrm{kg}$, up to a final dosage of $40 \mathrm{mg} / \mathrm{kg}$ per day.

\subsubsection{Behavioral Studies}

The Morris Water Maze (MWM) was performed at the end of the treatment period to evaluate the effects of AVCRI104P4 on cognition. During the last week of treatment, we planned the evaluation of the spatial navigation learning and memory of animals by assessing the escape latency (the time (s) the mice needed to find the hidden platform and therefore to escape from the water), the swim length (the length of the trajectory $(\mathrm{m})$ to reach the target), the swim speed (calculated quotient of swim length and escape latency) and the average distance to the target zone (m), as well as the number of target crossings and the abidance in the target quadrant during the probe trial. On the first MWM training day (day -7), some compound treated animals had problems to keep their head above the water, which might be ascribed to an overdosing of AVCRI104P4. Despite this handicap, AVCRI104P4 treated animals performed significantly better in terms of escape latency and swim length compared to vehicle treated controls. Indeed, animals treated with AVCRI104P4 found the hidden platform in a significantly shorter time (Figure 4A) and needed a significantly shorter way to find the hidden platform (Figure 4B) than animals receiving vehicle only. These results indicated a clear improvement of the short-term memory upon treatment with AVCRI104P4.

After a washout period of 5 days, the MWM test was repeated. Learning curves of days 1 to 4 of the postponed MWM training phase are depicted in Figure 4. During the main training phase, animals of both groups showed typical declining learning curves in terms of escape latencies and swimming paths. However, mice that had been treated with AVCRI104P4, which had shown improved short-term memory on the first MWM training day (day -7), did not show significantly improved spatial learning capabilities relative to controls after the washout period, i.e., in the absence of treatment, neither on day 1 nor on the following days (Figure 4A,B, and Figures S1 and S2, Supplementary Materials).

Similarly, no significant differences between treatment groups were detected when calculating the swimming speed (Figure 4C), the time spent in the target quadrant where the platform was hidden (abidance) and the number of target zone crossings (Figure 4D).

Thus, AVCRI104P4 treated animals started with significant lower escape latency and shorter way to find the hidden platform on training day -7 , when training was assessed short after the last application of $40 \mathrm{mg} / \mathrm{kg}$ AVCRI104P4, but its clear cognitive effects disappeared from training day 1 onwards, after the washout period, likely because these mice did not receive any compound for 5 days. 


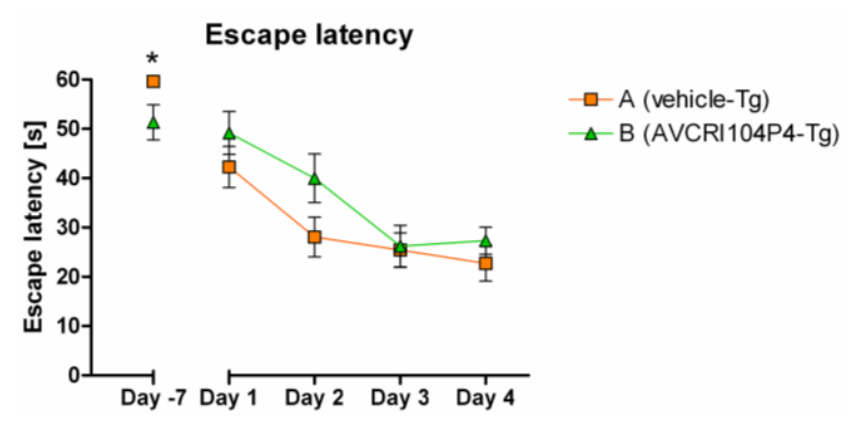

(A)

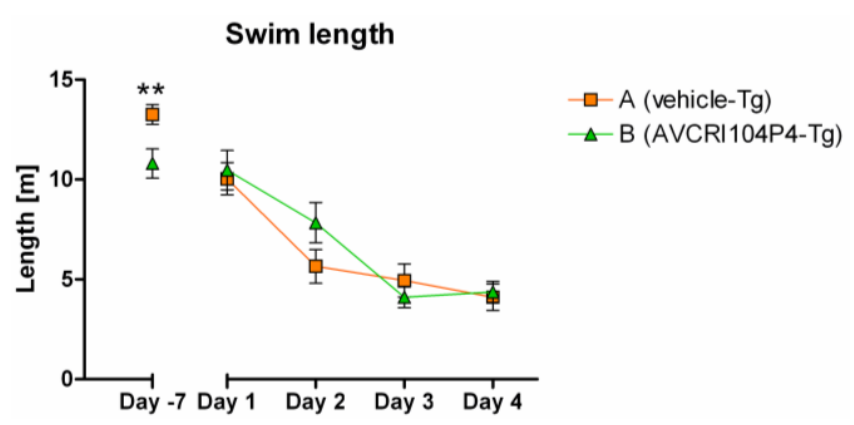

(B)

Swim speed

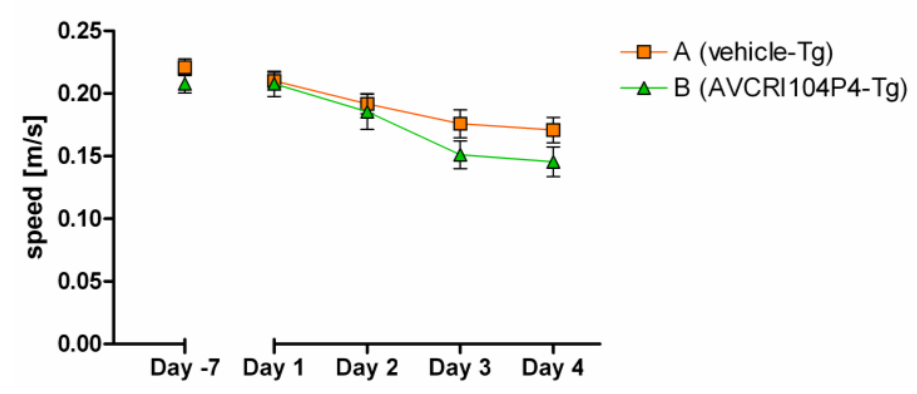

(C)

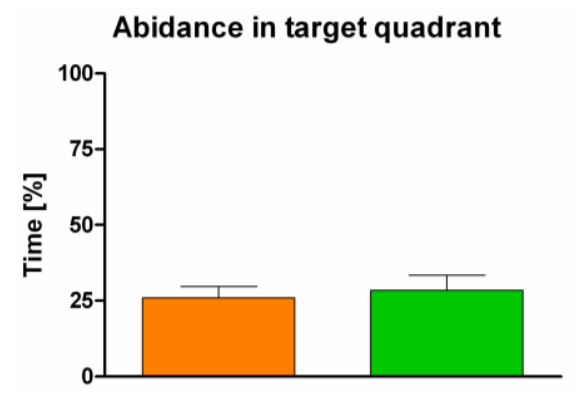

Number of target zone crossings

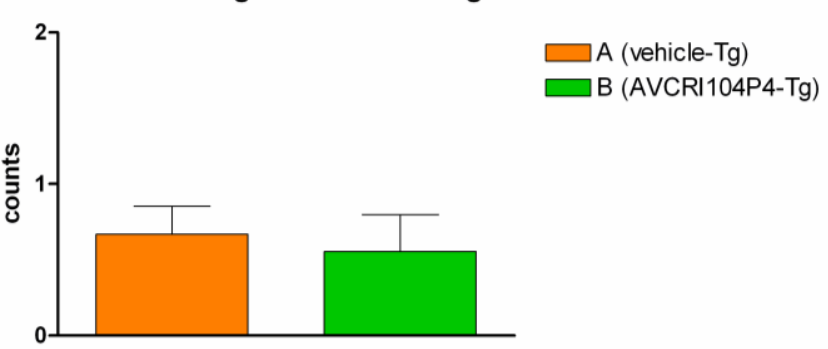

(D)

Figure 4. Graph represents (A) the latency to escape from the water (escape latency); (B) the swimming path to escape from the water (swim length); (C) the swim speed; and (D) the abidance in the target quadrant and number of target zone crossings in the MWM of hAPPSL transgenic animals treated with vehicle only (group A, orange) or AVCRI104P4 (group B, green) for 3 months. Data are presented as mean \pm SEM for each treatment group and day. Statistical significant differences were detected on the very first training day (-7) using Mann-Whitney test (for (A)) or unpaired t-test (for (B)). * indicates $p<0.05$. $* *$ indicates $p<0.01$. No statistical significant differences were detected for (C) and (D).

\subsubsection{Biochemistry and Histology}

$\mathrm{A} \beta 38, \mathrm{~A} \beta 40$, and $\mathrm{A} \beta 42$ levels were measured with an immunosorbent assay in CSF samples as well as in two brain homogenate preparations of transgenic mice, in which brain proteins from the left hemisphere of transgenic animals were extracted with diethylamine (DEA), which solubilizes non-plaque associated $A \beta$ such as monomeric to oligomeric structures or with formic acid (FA), which dissolves the total $\mathrm{A} \beta$ in the brain homogenates including plaques. Also, amyloid load was visualized with $6 \mathrm{E} 10$ antibody and thioflavin S (ThioS) staining and the signal was quantitatively analyzed in terms of the number of plaques, their total surface area, and their average size, both in the cortex and hippocampus. 
Unfortunately, treatment with AVCRI104P4 did not alter A $\beta 38, A \beta 40$, and A $\beta 42$ levels, neither in the CSF nor in DEA and FA brain homogenate preparations (Figure S3, Supplementary Materials), nor the number, area and mean size of 6E10 or ThioS objects in cortex and hippocampus (Figures S4-S6, Supplementary Materials) compared to vehicle treated controls. Similarly, plaque morphology, conformation of diffusely aggregated 6E10 immunoreactive amyloid and dense ThioS positive cores, and overall intracellular somal amyloid labeling was in general comparable between vehicle and AVCRI104P4 treatment groups (Figures S7-S9, Supplementary Materials).

Thus, contrary to our expectations, the moderately potent BACE-1 inhibitory activity observed

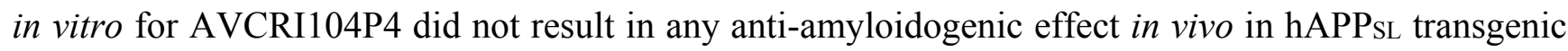
mice. Conversely, its potent in vitro anti-cholinesterase activity leads to a clear cognitive enhancing effect in transgenic mice, which disappears in the absence of treatment. All together, the results obtained in the in vivo efficacy studies point to a purely cholinergic but non disease-modifying effect of AVCRI104P4, thereby highlighting the need to improve its in vitro anti-amyloid/anticholinesterase activity ratio in future lead optimization.

\subsection{Hepatotoxicity Studies in HepG2 Cells}

The huprine Y moiety of AVCRI104P4 is structurally related to tacrine, the first approved anti-Alzheimer drug which was withdrawn from the market due to its hepatotoxic effects. Despite the large number of tacrine-based multitarget compounds or structurally related derivatives that are being developed, very few reports about their potential hepatotoxicity can be found in the literature. To address this issue in this work, the effects of AVCRI104P4 on cell viability and cytotoxicity were determined by MTT and LDH assays in HepG2 cells, a human liver hepatocellular carcinoma cell line, and compared with those produced by tacrine. HepG2 cells were incubated with rising dose concentrations of AVCRI104P4 and tacrine (0, 0.03, 0.1, 0.3, 0.8, 2.5, 7.4, 22.2, 66.7, and $200 \mu \mathrm{M})$. HepG2 cells showed a cytotoxic response to increasing dose concentrations of AVCRI104P4, which exhibited $\mathrm{EC}_{50}$ values of 8.8 and $9.7 \mu \mathrm{M}$ in the MTT and LDH assays, respectively (Figure 5). In the case of tacrine, minor toxic effects started at concentrations higher than $66.7 \mu \mathrm{M}$ but its EC50 values could not be determined since toxic concentrations were beyond the indicated concentration range. Hence, notwithstanding the apparent lack of toxicity of other huprine derivatives in chronic in vivo studies in different mouse models, we have found that AVCRI104P4 is more toxic to HepG2 cells than tacrine itself. Of note, similar results have been found for bis(7)-tacrine, an heptamethylene-linked dimer of tacrine under preclinical development that features a similar multitarget profile to that of AVCRI104P4 [39], for which hepatotoxicity in mice [40] and a higher cytotoxicity than that of tacrine in Caco-2 cells [41] have been recently reported. 


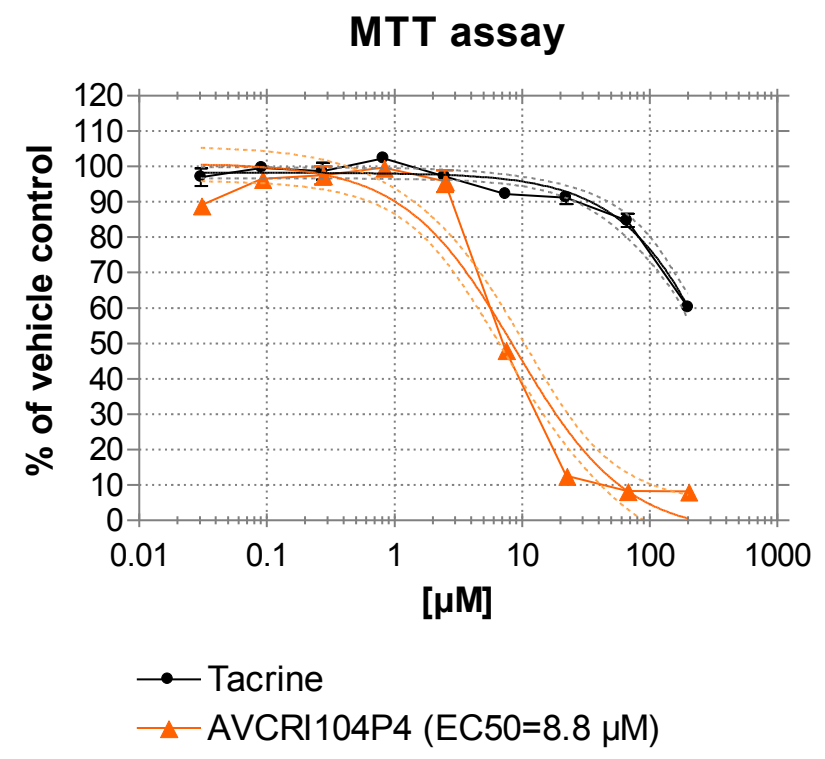

LDH assay

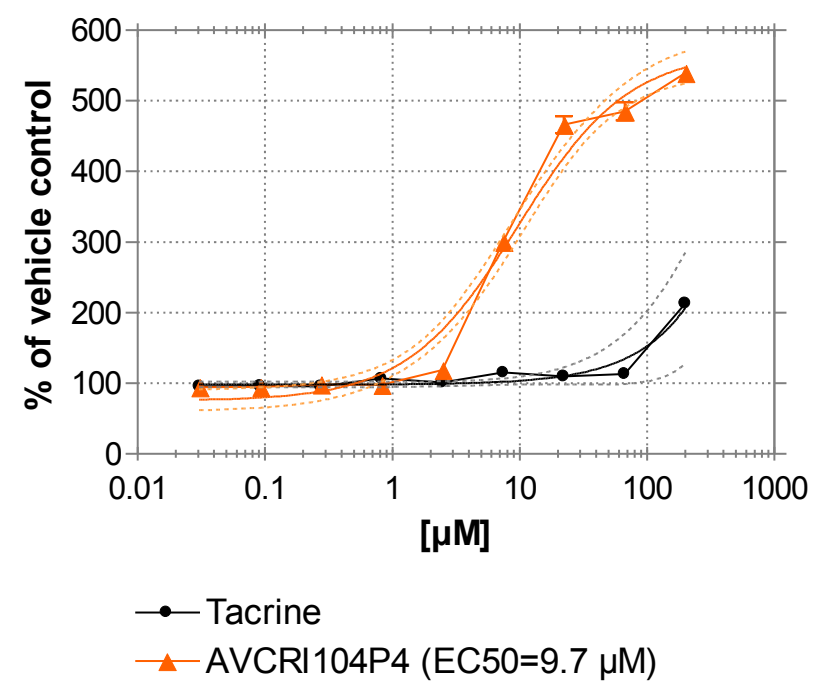

Figure 5. AVCRI104P4 and tacrine dose response in HepG2 cells. HepG2 cells were treated with AVCRI104P4 and tacrine at the indicated concentrations for $24 \mathrm{~h}$. Cell viability and cellular toxicity were determined according to MTT and LDH assays, respectively. Values are shown as mean $\pm \operatorname{SEM}(n=6)$.

\section{Experimental Section}

\subsection{Synthesis of AVCRI104P4}

\subsubsection{Chromatographic Screening}

The screening was performed on CHIRALPAK IA, CHIRALPAK IB and CHIRALPAK IC $(250 \times 4.6 \mathrm{~mm}$ i.d., $5 \mu \mathrm{m})$ supplied by Daicel Corporation (Tokyo, Japan) in LC and SFC. Flow rates in $\mathrm{LC}$ were set at 1 or $2 \mathrm{~mL} / \mathrm{min}$ (depending on retention) and temperature at $25^{\circ} \mathrm{C}$. The $\mathrm{SFC}$ screening was performed with $\mathrm{MeOH}, \mathrm{EtOH}$, and $\mathrm{i}-\mathrm{PrOH}$ as co-solvents in $\mathrm{CO}_{2}$ and extended to other polysaccharide-derived columns. The LC screening covered $n$-heptane mixtures with alcohols, THF, 
EtOAc, DCM, as well as pure acetonitrile and alcohols, with a number of combinations to optimise selectivity, retention and solubility. Optimisations were performed on the corresponding $20 \mu \mathrm{m}$ materials.

\subsubsection{Chromatographic Resolution of $( \pm)$-Huprine $Y$ at Preparative Scale}

Racemic huprine Y (66 g) was resolved into its two enantiomers using DCM/i-PrOH/DEA 90:10:0.1 as the mobile phase. The chiral stationary phase was ca. $1.5 \mathrm{Kg}$ of CHIRALPAK IC (20 $\mu \mathrm{m})$, available from Daicel Corporation, packed into a $250 \times 110 \mathrm{~mm}$ column. (-)-(7S,11S)-Huprine Y, (-)-(7S,11S)-1, was the first eluted enantiomer with this chromatographic method and its enantiomeric excess was $>99.8 \%$. Evaporation to dryness of the solvent yielded a thick oily material, which could be transformed into a solid by subsequent dissolution in DCM and evaporation. A total amount of $28.5 \mathrm{~g}$ of $(-)-(7 S, 11 S)-1$ was isolated as a brown amorphous powder and used for the next reaction without further purification. The non-target (second eluting peak, $(+)-(7 R, 11 R)-\mathbf{1}, 24.7 \mathrm{~g})$ was also recovered at high \% ee $(99.4 \%)$ to keep the overall high recovery.

\subsection{3. (-)-(7S,11S)-3-Chloro-12-[(3-\{4-[(5,6-dimethoxyindan-2-yl)methyl]piperidin-1-yl $\}$ propyl)} amino]-6,7,10,11-tetrahydro-9-methyl-7,11-metanocycloocta[b]quinoline, AVCRI104P4 $[(-)-(7 S, 11 S)-3]$

A suspension of (-)-huprine Y, (-)-(7S,11S)-1 (>99.8\% ee, $3.34 \mathrm{~g} 11.7 \mathrm{mmol})$ and finely powdered $\mathrm{KOH}(85 \%$ purity, $3.90 \mathrm{~g}, 58.5 \mathrm{mmol})$ in anhyd. DMSO $(48 \mathrm{~mL})$ was stirred, heating every $10 \mathrm{~min}$ approximately with a heat gun for $1 \mathrm{~h}$ and at room temperature for an additional $1 \mathrm{~h}$, and treated dropwise with a solution of crude 2 (5.00 $\mathrm{g}$ of a crude that could contain a maximum of $14.1 \mathrm{mmol}$ of 2, see Supplementary Materials) in anhydrous DMSO $(40 \mathrm{~mL})$ (previously warmed at $70{ }^{\circ} \mathrm{C}$ ). The reaction mixture was stirred at room temperature for 3 days, diluted with $\mathrm{H}_{2} \mathrm{O}(150 \mathrm{~mL})$, and $10 \mathrm{~N}$ $\mathrm{NaOH}(100 \mathrm{~mL})$, and extracted with DCM $(3 \times 200 \mathrm{~mL})$. The combined organic extracts were washed with $\mathrm{H}_{2} \mathrm{O}(2 \times 200 \mathrm{~mL})$, dried over anhydrous $\mathrm{Na}_{2} \mathrm{SO}_{4}$, and evaporated under reduced pressure to give a brown solid (10.9 g), which was purified through column chromatography (35-70 $\mu \mathrm{m}$ silica gel, EtOAc/hexane/Et $3 \mathrm{~N}$ 50:50:0.2), affording successively unreacted (-)-huprine $\mathrm{Y}$ (579 $\mathrm{mg}$ ) and AVCRI104P4 (2.94 g, 42\% yield). The IR, ${ }^{1} \mathrm{H}$ - and ${ }^{13} \mathrm{C}-\mathrm{NMR}$ data coincided with those previously reported [12]; Anal. calcd for $\mathrm{C}_{37} \mathrm{H}_{46} \mathrm{ClN}_{3} \mathrm{O}_{2} \cdot 2 \mathrm{HCl} \cdot 1.75 \mathrm{H}_{2} \mathrm{O}: \mathrm{C} 63.06 \%, \mathrm{H} 7.37 \%, \mathrm{~N} 5.96 \%, \mathrm{Cl}$ $15.09 \%$, found: $\mathrm{C} 63.16 \%, \mathrm{H} 7.33 \%, \mathrm{~N} 5.49 \%, \mathrm{Cl} 14.80 \%$. After several runs of this reaction, a total amount of $14 \mathrm{~g}$ of AVCRI104P4 was obtained.

\subsection{In Vivo Studies in Caenorhabditis elegans}

\subsubsection{C. elegans Strains}

CL2006, CL4176 and the control CL802 transgenic strains were obtained from the Caenorhabditis Genetic Center (University of Minnesota, Minneapolis, MN, USA) [34,42]. CL2006 constitutively expresses $A \beta 3-42$ in the body-wall muscles, while A $\beta 1-42$ was produced in muscle cells of CL4176 in a temperature-inducible manner. Nematodes were grown at $16{ }^{\circ} \mathrm{C}$ on solid Nematode Growth Medium (NGM) seeded with E. coli (OP50) for food. Age-synchronized animals were prepared as already described $[34,42]$ and day 1 synchronized worms were cultured on fresh NGM plates at $16{ }^{\circ} \mathrm{C}$. 


\subsubsection{Paralysis Assay}

The paralysis assay was performed in the CL4176 and CL802 worms as already described [35,36] Transgene expression was induced after $54 \mathrm{~h}$ of growth at $16^{\circ} \mathrm{C}$ by raising the temperature from 16 to $24{ }^{\circ} \mathrm{C}$. Eighteen hours after the temperature shift (L3 larval stage) nematodes were fed with different concentrations of AVCRI104P4 (5-300 $\mu \mathrm{M}, 100 \mu \mathrm{L} /$ plate, 100 worms/plate) or $100 \mu \mathrm{M}$ aldicarb. The paralysis of worms was determined $42 \mathrm{~h}$ after the temperature raise by scoring nematodes that did not move. Fifty $\mu \mathrm{M}$ tetracycline (Fluka, Buchs, Switzerland) administered $18 \mathrm{~h}$ after temperature rise was used as positive control. Synchronyzed CL2006 worms were fed, at L3 larval stage, with $100 \mu \mathrm{M}$ AVCRI104P4 (100 $\mu \mathrm{L} /$ plate, 100 worms/plate) and the number of nematodes paralyzed was scored $24 \mathrm{~h}$ later. Tetracycline was administered as a positive control.

\subsection{3. $\mathrm{A} \beta$ Expression}

Transgenic CL2006 and CL4176 worms treated with vehicle or $100 \mu \mathrm{M}$ AVCRI104P4 were processed as previously described [36]. The proteins were precipitated overnight with $\mathrm{MeOH}(1: 4 v / v)$ at $-20{ }^{\circ} \mathrm{C}$, before being resuspended in loading buffer and then spotted (5-10 $\mu \mathrm{g}$ ) onto nitrocellulose membranes (Merck Millipore, Darmstadt, Germany). Total protein visualization on the blotted membranes was performed by using $0.1 \%$ Ponceau Red solution (Sigma Aldrich, Saint Louis, MO, USA). Anti-A $\beta$ mouse monoclonal antibody (1:1000, Clone WO2, Merck Millipore) and peroxidase-conjugated anti-mouse $\operatorname{IgG}$ (1:5000, Sigma) were used as the primary and secondary antibodies, respectively. Mean volumes of immunoreactive and Red Ponceau dyed spots were analyzed (Progenesis SameSpots software 4.0, Nonlinear Dynamics Limited Keel House, Newcastle upon Tyne, UK; Nonlinear Dynamics, Newcastle upon Tyne, UK) and the mean values of volume of immunoreactive spot/volume of total Ponceau dyed proteins \pm SD were calculated.

\subsubsection{Staining of $\beta$-Amyloid}

Treated and non-treated fixed CL2006 worms [36] were stained with X-34 (1.0 mM) in Tris-HCl $(10 \mathrm{mM})$ for $4 \mathrm{~h}$ at room temperature and at $\mathrm{pH} 8.0$ [36,43]. The samples were destained and then observed with a IX-71 Olympus inverted fluorescence microscope, acquiring the images with a CCD camera. Quantification of amyloid burden in the anterior area of vehicle- and AVCRI104P4-treated nematodes ( $n=20$ per group) was carried out through the number of X-34 positive spots and the ratio $\mathrm{A} \beta$ deposits/anterior area was calculated.

\subsubsection{Statistical Analysis}

The effects of AVCRI104P4 on nematodes were compared with those of vehicle by standard tests (independent Student's $t$-test or One-way ANOVA test) and GraphPad Software (Prism version 4.0 for Windows, San Diego, CA, USA) was used to calculate the $\mathrm{IC}_{50}$ values, taking $p$ values $<0.05$ as statistically significant. 


\subsection{In Vivo Studies in Transgenic APPSL Mice}

\subsubsection{Animals and Treatment}

Male $\mathrm{APP}_{\mathrm{SL}}$ transgenic mice were housed as previously described [44], i.e., in individual ventilated cages, with constant $12 \mathrm{~h}$ light/dark cycle, at $24{ }^{\circ} \mathrm{C}$ and $40 \%-70 \%$ humidity, and providing standard rodent chow (Altromin, Lage, Germany) and tap water ad libitum. Animals were maintained in the fully AAALAC accredited QPS Austria animal facility under standardized conditions. Animal studies conformed to the Austrian guidelines for the care and use of laboratory animals (BGB1. 501/1989 in the appropriate valid version) and were approved by the Styrian Government, Austria (FA10A-78 Jo 85-2011). Twenty four mice at an age of 6 months ( \pm 2 weeks) were orally treated via gavage with vehicle or $40 \mathrm{mg} / \mathrm{kg} /$ day of AVCRI104P4 daily for 3 months ( $n=12$ each group). Eight animals were kept in reserve.

\subsubsection{Behavioural Studies}

The Morris Water Maze (MWM) was performed to assess spatial learning at the end of the treatment period. The MWM consisted of a white circular pool of a diameter of $100 \mathrm{~cm}$, filled with tap water at a temperature of $21 \pm 2{ }^{\circ} \mathrm{C}$. Each mouse had to perform three trials on each of four consecutive days, followed by a so-called probe trial (PT) $1 \mathrm{~h}$ after the last trial on day 4. Additionally, all animals had to perform a visual test after the PT on the last day to exclude visual problems as reason for behavioural results.

Descriptive statistical analysis was performed on all evaluated parameters. Data were averaged and represented as mean \pm standard error of mean (SEM). Outliers detected with Grubb's test were excluded from data analysis. Normality distribution of the values was tested with Kolmogorov Smirnov normality distribution test. Differences in MWM learning curves were evaluated by a Two-way ANOVA followed by Bonferroni's post-test. In order not to miss tendencies in the ANOVA, unpaired two-tailed $t$-tests or Mann Whitney tests (if values are not normally distributed) were calculated. Vehicle treated animals served as a control for AVCRI104P4 receiving mice.

\subsubsection{Tissue Sampling}

Mice were deeply sedated by standard inhalation anesthesia (Isoba ${ }^{\circledR}$, Essex, UK), CSF was collected and the samples were immediately frozen on dry ice and stored at $-80^{\circ} \mathrm{C}$ until used for $\mathrm{A} \beta$ determination. Following transcardial perfusion with $0.9 \%$ saline brains were also collected. Cerebellum was cut off and frozen and hemispheres were divided. Left hemispheres were frozen until used for biochemical analysis; right hemispheres for histological investigations were fixed by immersion in a freshly produced $4 \%$ mixture of paraformaldehyde/PBS ( $\mathrm{pH} 7.4$ ) for $1 \mathrm{~h}$ at room temperature, transferred to a $15 \%$ sucrose PBS solution until sunk at $4{ }^{\circ} \mathrm{C}$ to ensure cryoprotection, frozen in liquid isopentane, and stored at $-80{ }^{\circ} \mathrm{C}$. 


\subsubsection{Biochemistry}

\section{Brain Protein Extraction}

Left hemi-brain samples without cerebellum of transgenic animals were homogenized and separated into 2 fractions, the formic acid (FA) and diethylamine (DEA) fractions. Brain hemispheres were homogenized in Tissue Homogenization Buffer (THB) (20 mM Tris $\mathrm{HCl}$ pH 7.4, $250 \mathrm{mM}$ sucrose; $1 \mathrm{mM}$ EDTA; $1 \mathrm{mM}$ EGTA, protease inhibitor cocktail; $1 \mathrm{~mL}$ THB per $100 \mathrm{mg}$ brain tissue). For the extraction of deposited proteins (FA preparation), $200 \mu \mathrm{L}$ of the THB-homogenate were mixed with $440 \mu \mathrm{L}$ cold FA and sonicated. $400 \mu \mathrm{L}$ of the mixture was centrifuged for $1 \mathrm{~h}$ at $74,200 \mathrm{~g}$ at $4{ }^{\circ} \mathrm{C}$ and $210 \mu \mathrm{L}$ supernatant were neutralized with $4 \mathrm{~mL}$ FA neutralization solution (1 M TRIS; $0.5 \mathrm{M}$ $\mathrm{Na}_{2} \mathrm{HPO}_{4} ; 0.05 \% \mathrm{NaN}_{3}$ ). For the extraction of non-plaque-associated proteins (DEA preparation), $1 \mathrm{~mL}$ of the THB-homogenate was mixed with $1 \mathrm{~mL}$ DEA solution $(0.4 \% \mathrm{DEA} ; 100 \mathrm{mM} \mathrm{NaCl})$ and centrifuged for $1 \mathrm{~h}$ at $74,200 \mathrm{~g}$ at $4{ }^{\circ} \mathrm{C}$. $1.7 \mathrm{~mL}$ supernatant were neutralized with $170 \mu \mathrm{L}$ DEA Neutralization Solution (0.5 M Tris $\mathrm{HCl}, \mathrm{pH} 6.8)$.

Determination of $\mathrm{A} \beta$ Levels

In the two different brain homogenate fractions (FA and DEA) and in CSF of each transgenic mouse, $A \beta 38, A \beta 40$ and $A \beta 42$ levels were measured with a commercially available $A \beta$-kit from Mesoscale Discovery (Rockville, ND, USA). Samples from the brain preparations were analyzed in duplicate. Due to the small amount, CSF samples were single analyzed only. A $\beta$ levels were evaluated in comparison to peptide standards as ng $\mathrm{A} \beta$ per mg brain or ng $\mathrm{A} \beta$ per $\mathrm{mL}$ CSF.

\subsubsection{Histology}

Sectioning, Immunohistochemistry and Image Analysis

Seven cryo-sections per medio-sagittal level were sagittally cut at $10 \mu \mathrm{m}$ slice thickness on a Leica CM 3050S cryotome. Brain levels were chosen. The cut of the twelve levels started with a random section roughly corresponding to Figure 102 in the morphology atlas "The Mouse Brain" (Paxinos and Franklin, 2nd edition; approximately $0.24 \mathrm{~mm}$ lateral from midline), then sampling was continued uniformly and systematically, always retaining seven slices per level in series and discarding $230 \mu \mathrm{m}$ in between the levels.

\section{Determination of Plaque Load}

Plaque load was determined with 6E10 primary antibody (BioLegend formerly Covance, Dedham, MA, USA, \#SIG-39320, 1:1000 for $1 \mathrm{~h}$ at room temperature) directed against the human amyloid peptide (amino acids 1-16), visualized by a fluorescent secondary antibody (Cy3, Jackson ImmunoResearch Laboratories Inc., West Grove, PA, USA) and thioflavin S (Sigma, 0.5\% solution) staining against $\beta$-sheet structures in a double incubation. Additionally to standard protocol steps (drying, washing, primary and secondary incubations), slices were blocked with M.O.M blocking kit (Vector Laboratories Inc., Burlingame, CA, USA) before primary incubation to minimize unspecific secondary binding. 
Imaging

Mosaic images including the whole cortex and hippocampus were recorded on a Zeiss AxioImager.Z1 microscope using a high aperture lens and an AxioVision 4.8 software driven AxioCam MRm (10× lens NA 0.45, 1× optocoupler, Zeiss, Jena, Germany).

Evaluation of Amyloid Depositions and Plaque Load

For determination of histopathological variables a uniform systematic random set of five sagittally cut $10 \mu \mathrm{m}$ thick sections (deriving from the five different sagittal levels 2, 4, 7, 9, and 12) per brain were labelled and whole slice recordings were evaluated to collect a representative individual mean. Region size was measured by manual delineation of the hippocampus or neocortex. Labelings were quantified using automated image analysis software in a rater independent quantification (Image Pro Plus, version 6.2). IR objects were detected above an adaptive intensity threshold based on 8-bit 256 grey levels, which is defined as "mean signal in area of interest (AOI) $+1.2 \times$ standard deviation of mean signal in AOI". The level varied for the different labelings adjusted to the background fluorescence in the channel. Furthermore detected objects had to overcome a minimal size of $7 \mu \mathrm{m}^{2}$. All variable values were transported automatedly into a "csv" format raw data file together with the image title and included object number, surface area, mean and sum signal as well as individual threshold levels. Values were normalized to the invidual AOI size for each section and region, the values of the five sections averaged to the one individual mean.

Statistical Analysis

Descriptive statistical analysis was performed on all evaluated parameters, Kolmogorov Smirnov tests were performed to test normal distribution of data. Data in graphs are represented as mean $\pm \mathrm{SEM}$. Outliers were detected by Grubbs' test and were excluded from statistical analyses. Values of the five single measurements (from five different levels) per animal were averaged to one value per animal (individual mean) and group means were calculated with these averaged values. Group differences were calculated by an unpaired, two-tailed T-test.

\subsection{Hepatotoxicity Studies in HepG2 Cells}

In brief, HepG2 cells were cultured in 96-well plates at a density of 25,000 cells per well at $37{ }^{\circ} \mathrm{C}$ and $5 \% \mathrm{CO}_{2}$ in growth medium (MEM, 10\% FBS, 1\% Penc/Strep, $2 \mathrm{mM}$ glutamine, $1 \mathrm{mM}$ sodium pyruvate). After $24 \mathrm{~h}$, AVCRI104P4 and tacrine at the indicated concentrations were applied to the cells for a total of $24 \mathrm{~h}$. Cell viability and cellular toxicity were determined according to MTT and LDH assays, respectively. Cell viability was determined by the MTT assay using a plate-reader (570 $\mathrm{nm})$. MTT solution was added to each well in a final concentration of $0.5 \mathrm{mg} / \mathrm{mL}$. After $2 \mathrm{~h}$ the MTT containing medium was aspired. Cells were lysed in 3\% SDS and the formazan crystals were dissolved in $\mathrm{i}-\mathrm{PrOH} / \mathrm{HCl}$. Optical density was measured with a plate-reader at wavelength $570 \mathrm{~nm}$. Cell survival rate is expressed as optical density (OD). Data are shown as percentage of vehicle control.

Cellular toxicity was determined by the cytotoxicity detection kit (LDH, Roche, Mannheim, Germany). The assay was performed according to the manufacturer's instructions. Optical density was measured with a plate-reader at wavelength $492 \mathrm{~nm}$. Data are shown as percentage of vehicle control. 


\section{Conclusions}

In a program directed to the development of disease-modifying anti-Alzheimer compounds, AVCRI104P4 recently emerged as a very promising drug candidate by virtue of its in vitro multitarget profile, which encompasses a very potent $\mathrm{AChE}$ inhibitory activity (low nanomolar range) and moderately potent inhibitory activities against BChE, A $\beta$ aggregation, and BACE-1 (submicromolar or low micromolar range), as well as brain permeability. Because the potencies of a multitarget compound at its different targets may not necessarily have to be in a narrow range, in vivo efficacy studies may help to assess the adequate ratio of in vitro activities [19]. In this light, we embarked upon the in vivo testing of AVCRI104P4 to ascertain whether the anticholinesterase and anti-amyloid activities found in vitro might arise also in vivo.

In this work, we have scaled up all the synthetic steps leading to multigram amounts of AVCRI104P4, necessary to perform the planned in vivo studies. To this end, we have developed a novel methodology for the multigram chromatographic resolution of the immediate synthetic precursor huprine Y, which affords the required $(-)-(7 S, 11 S)$-enantiomer with higher efficiency and in higher enantiomeric excess than the low scale procedure, previously reported by us [26].

In vivo studies have been conducted firstly in two transgenic C. elegans strains expressing A $\beta 3-42$ or A $\beta 1-42$ either constitutively (CL2006) or upon induction by a temperature shift (CL4176). Interestingly, AVCRI104P4 protected in a dose-dependent manner CL4176 nematodes against the paralysis caused by $\mathrm{A} \beta$ oligomers ( $\mathrm{IC}_{50} 34 \mu \mathrm{M}$ ) and also counteracted the $\mathrm{A} \beta$-induced toxicity in CL2006 worms, albeit to a lower extent. These effects are specific and not related to its AChE inhibitory activity as indicated by the absence of any protective effect observed with the AChE inhibitor aldicarb. A putative effect on $\mathrm{A} \beta$ production by BACE-1 inhibition or on $\mathrm{A} \beta$ aggregation can be also excluded because, on the one hand, CL2006 and CL4176 transgenic worms overexpress A $\beta$ without intervention of BACE-1, and, on the other hand, AVCRI104P4 was not able to reduce insoluble A $\beta$ deposits in CL2006 worms.

To gain further insight into the potential in vivo effects of AVCRI104P4 on amyloid pathology and cognition, behavioral, biochemical and histological studies were carried out in a well-established mouse model of AD, namely in APPSL transgenic mice. AVCRI104P4, administered orally at a dose of $40 \mathrm{mg} / \mathrm{kg} /$ day for 3 months, led to a significant improvement of the short-term memory in the MWM compared with vehicle treated animals on the first training day, in spite of a severe muscular weakness displayed by some AVCRI104P4 treated animals. To overcome the problems due to that physical handicap, a one-week washout period without any treatment was applied before performing again the MWM. Unfortunately, after the washout period, transgenic mice that had received AVCRI104P4 did not display improved spatial learning and memory capabilities relative to transgenic controls. The observation of a clear cognitive effect while animals were being treated with AVCRI104P4 but the absence of positive effects one week after interruption of AVCRI104P4 treatment suggests that the potent AChE inhibitory activity that was found in vitro for AVCRI104P4 translates into an efficient compensation of the central cholinergic deficit and, hence, into a symptomatic relief, i.e., that AVCRI104P4 exerts a purely symptomatic action. A disease-modifying effect by AVCRI104P4 would have led to a minor degree of neurodegeneration in treated mice and to a better performance in the MWM even after the washout period. The absence of a disease-modifying effect was also evident in the biochemical and histological studies, where AVCRI104P4 treated animals had similar levels of A $\beta$ 
peptides in CSF and brain homogenates, as well as similar amyloid burden in cortex and hippocampus. These results suggest that AVCRI104P4 does not interfere either with A $\beta$ production or aggregation.

In summary, AVCRI104P4 exerts a significant cholinergic cognitive effect in a transgenic mouse model of $\mathrm{AD}$ but it has no effect on $\mathrm{A} \beta$ production ( $\mathrm{A} \beta$ peptides levels) and aggregation (amyloid burden) either in APPSL mice or in C. elegans, contrary to our expectactions in the light of its in vitro multitarget profile including inhibition of BACE-1 and $A \beta$ aggregation among other actions. Even though the mechanisms that are behind the protective effect of AVCRI104P4 in C. elegans remain unclear, observation of only a cholinergic but not an anti-amyloid effect for this compound in transgenic mice indicates that, besides a decreased toxicity, an improvement of the anti-amyloid/anticholinesterase activity ratio will be necessary in further lead optimization endeavours aimed at deriving a drug candidate with potential to modify the natural course of AD.

\section{Supplementary Materials}

Supplementary materials can be accessed at: http://www.mdpi.com/1420-3049/20/03/4492/s1.

\section{Acknowledgments}

This work was supported by Ministerio de Ciencia e Innovación (MICINN) (CTQ2011-22433), Generalitat de Catalunya (GC) (2009SGR1396), Fundación para el Desarrollo de la Investigación en Genómica y Proteómica (Fundación Genoma España), and Fundació Bosch i Gimpera-Vicerectorat d'Innovació i Transferència del Coneixement de la Universitat de Barcelona (Programa Fons Prova de Concepte 2010, Project FPC2010-19). C. elegans strains and E. coli OP50 were provided by CGC, which is funded by NIH Office of Research Infrastructure Program (P40 OD010440). This work was partially supported by Banca Intesa Sanpaolo (2014-2015). Fellowships from GC to IS and EV, from MICINN to TG, from IBUB to CG, and from Lifelong Learning Programme/Erasmus to MC are gratefully acknowledged.

\section{Author Contributions}

Irene Sola, Elisabet Viayna, Tània Gómez, Carles Galdeano, and Matteo Cassina carried out the large scale synthesis of intermediate compounds and AVCRI104P4; Pelayo Camps co-designed the synthetic part of the work; Margherita Romeo, Luisa Diomede, and Mario Salmona carried out the in vivo studies in C. elegans; Pilar Franco, Mireille Schaeffer, Diego Colantuono, and David Robin carried out the chromatographic screening and the large scale chromatographic resolution of huprine Y; Daniela Brunner and Birgit Hutter-Paier carried out the in vivo studies in APPSL mice. Nicole Taub carried out the toxicity studies in HepG2 cells. Luisa Diomede, Pilar Franco and Birgit Hutter-Paier also participated in the writing of the manuscript. Diego Muñoz-Torrero planned and coordinated the study and wrote the manuscript.

\section{Conflicts of Interest}

The authors declare no conflict of interest. 


\section{References}

1. Prince, M.; Albanese, E.; Guerchet, M.; Prina, M. World Alzheimer Report 2014: Dementia and Risk Reduction; Alzheimer's Disease International: London, UK, 2014. Available online: http://www.alz.co.uk (accessed on 20 February 2015).

2. Hardy, J.; Selkoe, D.J. The amyloid hypothesis of Alzheimer's disease: Progress and problems on the road to therapeutics. Science 2002, 297, 353-356.

3. Citron, M. Alzheimer's disease: Strategies for disease modification. Nat. Rev. Drug Discov. 2010, 9, 387-398.

4. Pimplikar, S.W. Reassessing the amyloid cascade hypothesis of Alzheimer's disease. Int. J. Biochem. Cell Biol. 2009, 41, 1261-1268.

5. Cavalli, A.; Bolognesi, M.L.; Minarini, A.; Rosini, M.; Tumiatti, V.; Recanatini, M.; Melchiorre, C. Multi-target-directed ligands to combat neurodegenerative diseases. J. Med. Chem. 2008, 51, 347-372.

6. Guzior, N.; Więckowska, A.; Panek, D.; Malawska, B. Recent development of multifunctional agents as potential drug candidates for the treatment of Alzheimer's disease. Curr. Med. Chem. 2015, 22, 373-404.

7. Geldenhuys, W.J.; van der Schyf, C.J. Rationally designed multi-targeted agents against neurodegenerative diseases. Curr. Med. Chem. 2013, 20, 1662-1672.

8. Chen, X.; Decker, M. Multi-target compounds acting in the central nervous system designed from natural products. Curr. Med. Chem. 2013, 20, 1673-1685.

9. Russo, P.; Frustaci, A.; Del Bufalo, A.; Fini, M.; Cesario, A. Multitarget drugs of plants origin acting on Alzheimer's disease. Curr. Med. Chem. 2013, 20, 1686-1693.

10. Capurro, V.; Busquet, P.; Lopes, J.P.; Bertorelli, R.; Tarozzo, G.; Bolognesi, M.L.; Piomelli, D.; Reggiani, A.; Cavalli, A. Pharmacological characterization of memoquin, a multitarget compound for the treatment of Alzheimer's disease. PLoS One 2013, 8, e56870.

11. Antequera, D.; Bolos, M.; Spuch, C.; Pascual, C.; Ferrer, I.; Fernandez-Bachiller, M.I.; Rodríguez-Franco, M.I.; Carro, E. Effects of a tacrine-8-hydroxyquinoline hybrid (IQM-622) on $\mathrm{A} \beta$ accumulation and cell death: Involvement in hippocampal neuronal loss in Alzheimer's disease. Neurobiol. Dis. 2012, 46, 682-691.

12. Viayna, E.; Gómez, T.; Galdeano, C.; Ramírez, L.; Ratia, M.; Badia, A.; Clos, M.V.; Verdaguer, E.; Junyent, F.; Camins, A.; et al. Novel huprine derivatives with inhibitory activity toward $\beta$-amyloid aggregation and formation as disease-modifying anti-Alzheimer drug candidates. ChemMedChem 2010, 5, 1855-1870.

13. Sussman, J.L.; Harel, M.; Frolow, F.; Oefner, C.; Goldman, A.; Toker, L.; Silman, I. Atomic structure of acetylcholinesterase from Torpedo californica: A prototypic acetylcholine-binding protein. Science 1991, 253, 872-879.

14. Inestrosa, N.C.; Alvarez, A.; Pérez, C.A.; Moreno, R.D.; Vicente, M.; Linker, C.; Casanueva, O.I.; Soto, C.; Garrido, J. Acetylcholinesterase accelerates assembly of amyloid- $\beta$-peptides into Alzheimer's fibrils: Possible role of the peripheral site of the enzyme. Neuron 1996, 16, 881-891.

15. De Ferrari, G.V.; Canales, M.A.; Shin, I.; Weiner, L.M.; Silman, I.; Inestrosa, N.C. A structural motif of acetylcholinesterase that promotes amyloid beta-peptide fibril formation. Biochemistry 2001, 40, 10447-10457. 
16. Castro, A.; Martinez, A. Targeting beta-amyloid pathogenesis through acetylcholinesterase inhibitors. Curr. Pharm. Des. 2006, 12, 4377-4387.

17. Muñoz-Torrero, D. Acetylcholinesterase inhibitors as disease-modifying therapies for Alzheimer's disease. Curr. Med. Chem. 2008, 15, 2433-2455.

18. Di, L.; Kerns, E.H.; Fan, K.; McConnell, O.J.; Carter, G.T. High throughput artificial membrane permeability assay for blood-brain barrier. Eur. J. Med. Chem. 2003, 38, 223-232.

19. Morphy, R.; Rankovic, Z. Designed multiple ligands. An emerging drug discovery paradigm. J. Med. Chem. 2005, 48, 6523-6543.

20. Zhang, T.; Nguyen, D.; Franco, P. Enantiomer resolution screening strategy using multiple immobilised polysaccharide-based chiral stationary phases. J. Chromatogr. A 2008, 1191, 214-222.

21. Franco, P.; Zhang, T. Common approaches for efficient method development with immobilised polysaccharide-derived chiral stationary phases. J. Chromatogr. B 2008, 875, 48-56.

22. Zhang, T.; Schaeffer, M.; Franco, P. Optimization of the chiral separation of a Ca-sensitizing drug on an immobilized polysaccharide-based chiral stationary phase. Case study with a preparative perspective. J. Chromatogr. A 2005, 1083, 96-101.

23. Bertz, S.H. Tetramethyl 3,7-dihydroxybicyclo[3.3.1]nona-2,6-diene-2,4,6,8-tetracarboxylate: A useful companion to Meerwein's ester. Topological analysis of bicyclo[3.3.1]nonane synthesis. J. Org. Chem. 1985, 50, 3585-3592.

24. Camps, P.; El Achab, R.; Font-Bardia, M.; Görbig, D.; Morral, J.; Muñoz-Torrero, D.; Solans, X.; Simon, M. Easy synthesis of 7-alkylbicyclo[3.3.1]non-6-en-3-ones by silica gel-promoted fragmentation of 3-alkyl-2-oxaadamant-1-yl mesylates. Tetrahedron 1996, 52, 5867-5880.

25. Ronco, C.; Jean, L.; Renard, P.-Y. Improved synthetic pathway for the derivatization of huprine scaffold. Tetrahedron 2010, 66, 7399-7404.

26. Camps, P.; Contreras, J.; Font-Bardia, M.; Morral, J.; Muñoz-Torrero, D.; Solans, X. Enantioselective synthesis of tacrine-huperzine A hybrids. Preparative chiral MPLC separation of their racemic mixtures and absolute configuration assignments by X-ray diffraction analysis. Tetrahedron Asymmetry 1998, 9, 835-849.

27. Camps, P.; Formosa, X.; Galdeano, C.; Gómez, T.; Muñoz-Torrero, D.; Scarpellini, M.; Viayna, E.; Badia, A.; Clos, M.V.; Camins, A.; et al. Novel donepezil-based inhibitors of acetyl- and butyrylcholinesterase and acetylcholinesterase-induced $\beta$-amyloid aggregation. J. Med. Chem. 2008, 51, 3588-3598.

28. Volovik, Y.; Carvalhal Marques, F.; Cohen, E. The nematode Caenorhabditis elegans: A versatile model for the study of proteotoxicity and aging. Methods 2014, 68, 458-464.

29. Hassan, W.M.; Dostal, V.; Huemann, B.N.; Yerg, J.E.; Link, C.D. Identifying A $\beta$-specific pathogenic mechanisms using a nematode model of Alzheimer's disease. Neurobiol. Aging 2015, 36, 857-866, doi:10.1016/j.neurobiolaging.2014.10.016.

30. Li, J.; Le, W. Modeling neurodegenerative diseases in Caenorhabditis elegans. Exp. Neurol. 2013, 250, 94-103.

31. Sashidhara, K.V.; Modukuri, R.K.; Jadiya, P.; Prasad Dodda, R.; Kumar, M.; Sridhar, B.; Kumar, V.; Haque, R.; Imran Siddiqi, M.; Nazir, A. Benzofuran-chalcone hybrids as potential multifunctional agents against Alzheimer's disease: Synthesis and in vivo studies with transgenic Caenorhabditis elegans. ChemMedChem 2014, 9, 2671-2684. 
32. Cao, Y.; Wang, L.; Lin, Z.; Liang, F.; Pei, Z.; Xu, J.; Gu, Q. Dehydroabietylamine derivatives as multifunctional agents for the treatment of Alzheimer's disease. Med. Chem. Commun. 2014, 5, 1736-1743.

33. Cao, Y.Y.; Wang, L.; Ge, H.; Lu, X.L.; Pei, Z.; Gu, Q.; Xu, J. Salvianolic acid A, a polyphenolic derivative from Salvia miltiorrhiza bunge, as a multifunctional agent for the treatment of Alzheimer's disease. Mol. Divers. 2013, 17, 515-524.

34. Link, C.D. Invertebrate models of Alzheimer's disease. Genes Brain Behav. 2005, 4, 147-156.

35. Diomede, L.; Rigacci, S.; Romeo, M.; Stefani, M.; Salmona, M. Oleuropein aglycone protects transgenic $C$. elegans strains expressing A $\beta 42$ by reducing plaque load and motor deficit. PLoS One 2013, 8, e58893.

36. Diomede, L.; Cassata, G.; Fiordaliso, F.; Salio, M.; Ami, D.; Natalello, A.; Doglia, S.M.; De Luigi, A.; Salmona, M. Tetracycline and its analogues protect Caenorhabditis elegans from $\beta$ amyloid-induced toxicity by targeting oligomers. Neurobiol. Dis. 2010, 40, 424-431.

37. Beeg, M.; Diomede, L.; Stravalaci, M.; Salmona, M.; Gobbi, M. Novel approaches for studying amyloidogenic peptides/proteins. Curr. Opin. Pharmacol. 2013, 13, 797-801.

38. Stoilova, T.; Colombo, L.; Forloni, G.; Tagliavini, F.; Salmona, M. A new face for old antibiotics: Tetracyclines in treatment of amyloidoses. J. Med. Chem. 2013, 56, 5987-6006.

39. Zhang, L.; Yu, H.; Li, W.M.; Cheung, M.C.; Pang, Y.P.; Gu, Z.M.; Chan, K.; Wang, Y.T.; Zuo, Z.; Han, Y.F. Preclinical characterization of intestinal absorption and metabolism of promising anti-Alzheimer's dimer bis(7)-tacrine. Int. J. Pharm. 2008, 357, 85-94.

40. Pan, S.Y.; Yu, Z.L.; Dong, H.; Lee, N.T.K.; Wang, H.; Fong, W.F.; Han, Y.F.; Ko, K.M. Evaluation of acute bis(7)-tacrine treatment on behavioral functions in 17-day-old and 30-day-old mice, with attention to drug toxicity. Pharmacol. Biochem. Behav. 2007, 86, 778-783.

41. Qian, S.; He, L.; Mak, M.; Han, Y.; Ho, C.-Y.; Zuo, Z. Synthesis, biological activity, and biopharmaceutical characterization of tacrine dimers as acetylcholinesterase inhibitors. Int. J. Pharm. 2014, 477, 442-453.

42. Wu, Y.; Wu, Z.; Butko, P.; Christen, Y.; Lambert, M.P.; Klein, W.L.; Link, C.D.; Luo, Y. Amyloid- $\beta$-induced pathological behaviors are suppressed by Ginkgo biloba extract EGb 761 and ginkgolides in transgenic Caenorhabditis elegans. J. Neurosci. 2006, 26, 13102-13113.

43. Styren, S.D.; Hamilton, R.L.; Styren, G.C.; Klunk, W.E. X-34, a fluorescent derivative of Congo red: A novel histochemical stain for Alzheimer's disease pathology. J. Histochem. Cytochem. 2000, $48,1223-1232$.

44. Havas, D.; Hutter-Paier, B.; Ubhi, K.; Rockenstein, E.; Crailsheim, K.; Masliah, E.; Windisch, M. A longitudinal study of behavioral deficits in an A $\beta$ PP transgenic mouse model of Alzheimer's disease. J. Alzheimers Dis. 2011, 25, 231-243.

Sample Availability: Samples of the compound AVCRI104P4 are available from the authors.

(C) 2015 by the authors; licensee MDPI, Basel, Switzerland. This article is an open access article distributed under the terms and conditions of the Creative Commons Attribution license (http://creativecommons.org/licenses/by/4.0/). 